\title{
Does Television Terrify Tourists? \\ Effects of US Television News on Demand for Tourism in \\ Israel $^{\S}$
}

\author{
David Fielding ${ }^{\Uparrow}$ and Anja Shortland ${ }^{\dagger}$
}

March 2007

\begin{abstract}
In this paper we analyze a time series measuring the monthly flow of US tourists to Israel over the period 1997-2006. We pay particular attention to the response of tourists to variations in the intensity the Israeli-Palestinian conflict, drawing a distinction between actual conflict intensity and the intensity with which the conflict is reported in the US television media. We find that different dimensions of the conflict affect tourists in different ways. For some (but not all) dimensions of the conflict, reported intensity matters more than actual intensity.
\end{abstract}

JEL classification: L83; D89; M39

Keywords: media; tourism; violence

$\S$. We are grateful for the support of ESRC Grant RES-000-22-0312, which funded the project of which this paper is a part. Thanks also to Paul Frijters, Paul Hansen, Arye Hillman and Frank Stähler, seminar participants at the Universities of Leicester, Canterbury and Otago and three anonymous referees for comments on previous drafts of this paper. All remaining errors and omissions are our own.

` Corresponding author: Department of Economics, University of Otago, PO Box 56, Dunedin 9001, New Zealand; e-mail dfielding@business.otago.ac.nz. Telephone ++64-3-479-8653; fax ++64-3-4798174.

${ }^{\dagger}$ Department of Economics and Finance, Brunel University, Uxbridge, Middlesex UB8 3PH. 


\section{Introduction}

This paper analyses the impact of the media on US tourist decisions about whether to travel to Israel. It draws on two strands of economic thought. The first relates to media influence on the perceived risk associated with potentially dangerous activities. Individual households may have imperfect information about the risks associated with, for example, eating certain kinds of food or visiting certain neighbourhoods. When information is costly, they may use the intensity of media coverage of a hazardous activity as an indicator of the level of risk involved, interpreting intense media interest as a sign of concern among those who are better informed. Alternatively, we might abandon strict economic rationality in favour of the psychological model of Tversky and Kahneman (1973), in which the frequency with which events of a certain type come to mind conditions the perceived frequency of such events in everyday life. More intense media coverage of dangers increases their perceived frequency, regardless of the true risks involved. ${ }^{1}$

The importance of the media in conditioning perceptions is well documented in several areas of economics and other social sciences. Criminologists have used household survey data to examine the extent to which the intensity of coverage of violent crime on television news channels affects the perceived risk of being a victim of crime. The hypothesis that the television news media condition people's perceptions - know as "cultivation theory" - dates back to Gerbner and Gross (1976). Recent studies provide substantial evidence for the importance of news coverage of crime in conditioning perceptions. Romer et al. (2003) analyse data from the US General Social Survey to show that individuals' perceptions of the frequency of crime, conditional on a range of socio-economic characteristics, depend not only on actual crime in their locality, but also the intensity of crime reporting in the local television media. This evidence is reinforced by more detailed surveys of individual cities, showing that people watching more television news perceive there to be a higher level of violent crime, ceteris paribus (Romer et al., 2003; Gross and Aday, 2003; Chiricos et al., 1997).

The focus of attention in criminology is on respondents' self-reported perceptions of risk. There is, as far as we are aware, no evidence on the extent to which television reports of violent crime affect people's behaviour. However, there is econometric evidence that media reporting of health risks has a direct impact on consumer behaviour. Verbeke and Ward (2001) analyse time-series data on Belgian meat consumption during the period of the BSE crisis; they show that demand for beef was highly sensitive to time-series variations in the intensity of media reports about the risk of BSE. Other studies reporting a significant media effect on demand for food during health scares include Mazzochi (2004) and Kalaitzandonakes et al. (2004). In some papers, for example, Piggot and Marsh (2004), the 
authors note that the media effect is economically and statistically significant, but short-lived. One interpretation of these results is that media reports produce a Tversky-Kahneman effect, but one that lodges only in people's short-term memory. However, the results are also consistent with rational consumers who assume that journalists are better informed about short-term variations in the level of risk.

The second strand on which we draw (a large part of which is reviewed by Frey et al., 2004) relates to the economic consequences of violent conflict. Much of the politically motivated violence in the modern world takes the form of low-intensity conflict which might not disrupt economic production in any substantial way. However, it can still have substantial demand-side effects, especially when tourism is a major export industry, with consequences for the financial sector (Eldor and Melnick, 2004). Evidence for the effect of political violence on the tourism sector is reported in Enders and Sandler (1991) for Spain, Enders et al. (1992) for Austria, Italy and Greece, Drakos and Kutan (2003) for Greece, Israel and Turkey and Sloboda (2003) for the USA. In related work, Drakos (2004) examines the effects of 9/11 on various airline companies. One paper that focuses explicitly on Israel is Fleischer and Buccola (2002). This paper shows that foreign demand for tourist accommodation is particularly sensitive to violence in the region, whereas local demand is quite insensitive; these effects are reflected in local financial markets.

Such papers provide rigorous and compelling evidence on the effects of political violence on tourism. However, they leave one key issue unresolved. To the extent that they employ accurate measures of conflict intensity, rather than the intensity with which the conflict is reported by the popular media, they do not directly address the role of the media in conditioning perceptions of risk. ${ }^{2}$ In order to analyse the role of the popular media, we need to distinguish between the impact of actual violence on tourists' decisions and the impact of reported violence, as in the criminology literature. Our paper addresses this issue using monthly tourism and conflict intensity data for Israel during the most recent IsraeliPalestinian conflict (the Al Aqsa Intifada, beginning in October 2000), and corresponding television media data from the United States. While not a full-scale civil war, the Intifada represents a continuous ongoing conflict, rather than a series of isolated conflict events.

\section{The Structure of the Empirical Model $^{3}$}

Appendix 1 explains the choice-theoretic framework from which we derive the regression equations used to test hypotheses about the causes of monthly variations in the volume of tourist flows from the US to Israel. Our regression equations are of the form:

$$
\beta(\mathrm{L}) \ln \left(T I S_{t} / T E U_{t}\right)=A(\mathrm{~L}) \boldsymbol{X}_{t}+\Sigma_{s} \theta_{s} \cdot h_{s t}+\phi_{1} \cdot P S_{t}+\phi_{2} \cdot N Y_{t}+\varepsilon_{t}
$$


$T I S_{t}$ represents the number of US tourists visiting Israel in month $t$; TEU $U_{t}$ is a scale variable, measuring US tourist flows to a relatively safe location, Europe. Later, we will explore the sensitivity of our results to using an alternative scale variable. $\boldsymbol{X}_{t}$ represents a vector of timevarying factors that might impact on the relative attractiveness of Israel as a tourist destination, including indicators of both actual and reported violence. $\beta(\mathrm{L})$ is a lag

polynomial operator capturing persistence in tourism flows. $\boldsymbol{A}(\mathrm{L})$ is a vector of lag polynomial operators capturing lagged effects in $\boldsymbol{X} . \varepsilon_{t}$ is a regression residual. The other elements of equation (1) capture seasonal effects: $h_{s t}$ is an intercept specific to month $s$ of the year, $P S_{t}$ is a dummy variable for the occurrence of Passover in month $t$ and $N Y_{t}$ a dummy variable for the occurrence of the Jewish New Year. ${ }^{4}$

Our dependent variable is constructed from two data sources. Monthly Israeli tourism data are published by the Central Bureau of Statistics and are available online at www.cbs.gov.il. The data used to measure $T I S_{t}$ are those for the number of Americans checking into tourist hotels. ${ }^{5}$ One alternative data source is the number of Americans recorded entering Israel by the customs service. However, in 2001 the Israeli customs service changed its definition of "American" from US resident to US passport holder, so we cannot use customs data to measure US tourist flows for whole of the Intifada period. For the scale variable $T E U_{t}$ we use monthly figures from the dataset published by the ITA Office of Tourism and Travel Industries (http://tinet.ita.doc.gov), which reports the number of American tourists departing for Europe.

The hotels data are available from January 1996, and Figure 1 depicts the $\ln \left(T I S_{t} / T E U_{t}\right)$ series constructed using these data for the period January 1996 - June 2006. (The figure also incorporates some trend lines to be discussed later.) It can be seen that there is a pronounced dip in $\ln \left(T I S_{t} / T E U_{t}\right)$ after the onset of the Intifada in October 2000, but that Israeli tourism slowly recovers toward the end of the sample period, when there is some diminishment in the intensity of the conflict. It is not clear whether this time series is stationary; stationarity test statistics are discussed in the next section.

\section{Figure 1 and Table 1 here}

In the results section below, we present five alternative models, each incorporating a slightly different set of variables in the $\boldsymbol{X}$ vector; the full list of models is presented in Table 1. These variables reflect different dimensions of the conflict, both actual and reported. Model 1 includes two reported conflict intensity series. These are constructed from the Reuters Factiva database, which records daily transcripts from the main US television news shows from January 1997 onwards. The three most popular shows are the NBC Nightly News, CBS 
Evening News and ABC World News Tonight. Our main results are based on the World News Tonight data. The comparison of our main results with the alternatives - using other news shows instead of World News Tonight, or aggregating over different shows - is discussed later. From the Factiva database we construct two monthly time series: $P A L^{W N T}$ and $I F K^{W N T}$. The first measures the number of conflict-related Palestinian fatalities reported on the news show, and the second measures the number of Israeli and foreign fatalities. The two times series exclude repeat coverage of the same fatalities and retrospective coverage of events that took place months earlier, for which separate time series can be created, as discussed later.

Corresponding to $P A L^{W N T}$ and $I F K^{W N T}$ are the series $P A L^{N R P}$ and $I F K^{N R P}$, the totals for monthly Palestinian and Israeli fatalities not reported on World News Tonight. These series are constructed from actual fatality data published by the human rights organisation B'Tselem (www.btselem.org). ${ }^{6}$ There is very little discrepancy between the B'Tselem data and other official sources, such as the Israeli Defense Force (IDF) website, www1.idf.il, or the Palestinian Red Crescent Society website, www.palestinercs.org. Indeed, the actual figures correspond very closely to the numbers that would be produced from a careful reading of a serious newspaper such as the Jerusalem Post, or even the New York Times. If tourists base their decisions on information in the quality media then there will be no cultivation effect from the television media, and the effect of $P A L^{W N T}\left(I F K^{W N T}\right)$ on tourist flows should be no different from that of $P A L^{N R P}\left(I F K^{N R P}\right)$.

A higher number of casualties among Israelis and foreign visitors represents a direct threat to tourists, and for this reason it may reduce tourist numbers. However, this effect may be mitigated if a higher level of casualties evokes more sympathy for Israelis and prompts more of the "solidarity" tourism promoted by US groups such as United Jewish Communities. Palestinian casualties represent less of a direct threat to tourists, but they may increase the perceived level of threat, if there is a perception of a "cycle of violence" in which higher Palestinian casualties now lead to a greater threat to tourists in the immediate future. Jaeger and Paserman (2005) find no evidence for such a cycle, but there might still be a perception that such a cycle exists. (Moreover, even a statistically literate tourist is likely to be more concerned with Type II errors than with Type I errors when evaluating the null that there is no such cycle.) Alternatively, a rise in Palestinian casualties could prompt tourists sympathetic to the Palestinian cause to boycott Israel, as promoted by US groups such as the Palestine Solidarity Movement. Moreover, if tourists have to avoid areas where Palestinian casualties occur (for example, Bethlehem) then their vacation as a whole may be less enjoyable.

The four time series, $P A L^{W N T}, I F K^{W N T}, P A L^{N R P}$ and $I F K^{N R P}$, all appear to be approximately log-normally distributed, although all four are sometimes equal to zero, 
especially before the onset of the Intifada in October 2000. For this reason, Model 1 incorporates them in the $\boldsymbol{X}$ vector as $\ln \left(1+P A L^{W N T}\right), \ln \left(1+I F K^{W N T}\right), \ln \left(1+P A L^{N R P}\right)$ and $\ln \left(1+I F K^{N R P}\right)$. These four series are depicted in Figure 2. Table 2 lists correlation coefficients for the four variables. There is a moderately high correlation between $\ln \left(1+P A L^{W N T}\right)$ and $\ln \left(1+I F K^{W N T}\right)$, as there is between the corresponding non-reported fatality series. However, correlations between the reported and non-reported series are much smaller: the short-run variation in reported conflict events is not a particularly accurate reflection of what is happening on the ground. Moreover, all of the correlation coefficients drop markedly when we restrict our attention to the high violence period, 2001-2004.

It can be seen from Figure 2 that the peak of the violence is in March 2002, when there were 12 suicide bomb attacks (the next highest number is five). March 2002 is highly atypical of the rest of the period; at such high levels of violence the response of tourism could exhibit non-linearities not seen at other times, and for this reason Model 1 includes a dummy variable for this month. It can also be seen that the onset of the Intifada in October 2000 constitutes a definite structural break. At the time, tourists may well have wondered whether Israel was going to descend into a full-scale civil war. For this reason, Model 1 includes a dummy for October-November 2000.

Finally, we must recognise that the Israeli-Palestinian conflict is reported in the context of a high level of violence across the region, particularly in Iraq. The Iraqi conflict has been reported virtually every day in the American media since the invasion of FebruaryMarch 2003, but we do not include a variable for the number of casualties reported in Iraq. It is unlikely that tourists perceive there to be a high correlation between Iraqi violence (trending upwards over 2005-6) and Israeli violence (trending downwards over 2005-6). Nevertheless, at the onset of the Second Gulf War in February-March 2003 tourists may have perceived there to be some risk of a retaliatory attack on Israel. For this reason, we include a dummy variable for these two months.

Figure 2 and Table 2 here

Model 2 is a minor modification of Model 1. Because we are using logarithmic transformations, a model with reported and non-reported fatalities is not identical to one with reported and total fatalities. In order to check whether our results are sensitive to this difference, Model 2 replaces the two non-reported fatality series with one for total Palestinian fatalities, $\ln (1+P A L)$, and one for total Israeli fatalities, $\ln (1+I F K)$. In the absence of any cultivation effect, the reported fatality series should be statistically insignificant in this model. 
One potential criticism of Models 1-2 is that they do not disaggregate Israeli and foreign fatalities. In Models 3-5 we consider alternative forms of disaggregation. First of all, in Model 3, we distinguish between Israeli and foreign fatalities occurring in the West Bank and Gaza $\left(I F K^{W B G}\right)$ and those occurring west of the Green Line $\left(I F K^{I S R}\right)$. Fatalities in the West Bank and Gaza may represent less of a threat to tourists than fatalities elsewhere, because Palestinian areas locations are easy to avoid. (Tourist numbers in West Bank towns such as Bethlehem have fallen almost to zero since the start of the Intifada.) On the other hand, it is possible that a reduction in tourism following a rise in Israeli casualties is partly offset by a solidarity effect among those with high level of political sympathy for the State of Israel. If casualties among Israeli settlers evoke less sympathy than casualties elsewhere, then the settler casualty coefficient may be greater in absolute value. Therefore, we do not have any $a$ priori view on the relative sizes of the two coefficients.

In Models 4-5 we distinguish between Israeli and foreign fatalities caused by suicide bomb attacks and fatalities caused by other types of attack. Suicide bomb attacks typically target a particular public location, but many other types of attack target specific individuals. Possibly, tourists perceive the former to represent a greater threat than the latter. Model 4 replaces $I F K$ with $I F K^{S U I}$ (the number of Israeli and Foreign fatalities in suicide bomb attacks) and $I F K^{O T H}$ (the number of Israeli and Foreign fatalities in other attacks). Model 5 uses the number of suicide bomb attacks (NSU) instead $I F K^{S U I}$. If the number of fatalities in a particular attack is perceived by potential tourists to be largely a consequence of chance, then the number of fatalities matters less than the number of attacks.

There are two obvious omissions in Models 1-5. First of all, we do not disaggregate according to both the location of the attack and the type of attack. As can be seen in Table 2 above, there is a very high correlation between $\ln \left(1+I F K^{S U I}\right)$ and $\ln \left(1+I F K^{I S R}\right)$, as there is between $\ln \left(1+I F K^{O T H}\right)$ and $\ln \left(1+I F K^{W B G}\right)$. In practice, the majority of suicide bomb attacks are west of the Green Line, and the majority of other attacks on Israelis are in the West Bank and Gaza. If we disaggregated fatalities any further, then the t ratios would exhibit a large downward bias, preventing any sensible inference from the model. Secondly, we do not disaggregate reported fatalities in the same way as actual fatalities. In order to see why, consider the following transcript of a typical World News Tonight report from the $4^{\text {th }}$ March 2002, which follows a description of IDF attacks on Palestinians.

"That follows one of Israel's worst weekends since this conflict began. 21 Israelis dead in less than 24 hours. Palestinian groups have been hitting on all fronts. Suicide attacks against civilians, shooting attacks against Israeli settlers and soldiers. One 
Palestinian sharpshooter managed to kill 10 Israelis, including seven soldiers at this checkpoint, and then he got away."

The report is specific about the total number of Israeli casualties, but vague about the proportion occurring in the West Bank and Gaza, and about the proportion occurring in suicide bomb attacks. We cannot use this report to construct a precise disaggregation of Israeli fatalities, and nor could the potential tourists who originally watched it.

\section{Regression Results}

\subsection{Stationarity test statistics}

Any inference based on critical values in the regression results depends on establishing the stationarity of the time series depicted in Figures 1-2. In testing the null that the time series are I(1) against the alternative that they are stationary, we must deal with two complications. Firstly, all of the series exhibit a clear structural break in late 2000, although the precise date of the break is not clear. Some of the series seem to exhibit a break a month or two after the onset of the Intifada in October 2000. Secondly, with the exception of the dependent variable, the series often take zero values before the break point, so models assuming a Gaussian distribution are inappropriate. Techniques for estimating the degree of persistence in censored distributions do exist (for example, De Jong, 1997), but these techniques require far more observations than we have.

In testing for stationarity we take a two-pronged approach. For the dependent variable we apply the method of Leybourne et al. (1998), which is used to test for stationarity around a smooth transition centred on an unknown breakpoint. That is, we fit the model

$$
\ln \left(T I S_{t} / T E U_{t}\right)=a_{0}+a_{1} \cdot t+\frac{a_{2}+a_{3} \cdot t}{1+\exp \left(-a_{4} \cdot\left[t-a_{5}\right]\right)}+u_{t}
$$

and then apply a Dickey-Fuller test to the residual $u_{t}$. Critical values for the resulting $t$ statistic are given in the Leybourne et al. paper. The robustness of the result is checked by submitting the data to both a standard ADF test and the test of Harvey and Mills (2002), which allows for two breakpoints by replacing equation (2) with

$$
\ln \left(T I S_{t} / T E U_{t}\right)=a_{0}+a_{1} \cdot t+\frac{a_{2}+a_{3} \cdot t}{1+\exp \left(-a_{4} \cdot\left[t-a_{5}\right]\right)}+\frac{a_{6}+a_{7} \cdot t}{1+\exp \left(-a_{8} \cdot\left[t-a_{9}\right]\right)}+u_{t}
$$

The two fitted smooth transitions are depicted in Figure 1 above. Table 3 reports the stationarity test statistics. If we do not allow for any structural break and apply a standard $\mathrm{ADF}$ test, then we can reject the null that the series is $\mathrm{I}(1)$ only at the $10 \%$ level. However, applying either the Leybourne et al. test or the Harvey and Mills test, we can reject the null at 
the $1 \%$ level. On balance, there seems to be clear evidence that the series is stationary, at least if we allow for a smooth transition.

We do not use the same method in testing the explanatory variables, because it is unrealistic to fit a Gaussian distribution to data before the end of 2000. Instead, we restrict attention to the period 2001(1)-2006(6), and apply a standard ADF test to each of the series over this period. The results are reported in Table 4 . In one case $-\ln \left(1+I F K^{I S R}\right)-$ the null that the series is $\mathrm{I}(1)$ can be rejected at only the $10 \%$ level, but in all other cases the null can be rejected at the $5 \%$ level or less. Given that $\ln \left(1+I F K^{I S R}\right)$ is approximately a linear combination of the other variables in the table (with an $\mathrm{R}^{2}$ of 0.97 ), it seems safe to assume that all of the variables are stationary over the period 2001(1)-2006(6). We will further assume that the data are also stationary over the period 1997(1)-2000(12), although strictly speaking this assumption in untested.

\section{Tables 3-5 here}

\subsection{The fitted model}

Our main results are presented in Table 5, which lists the steady-state regression coefficients in each of the five models, that is, the vector $\beta(1)^{-1} A(1)$, along with the corresponding standard errors. The full set of regression coefficients is reported in Appendix 2; we use a second order lag in $\beta($.) and a first-order lag in $A($.$) , higher order lags being statistically$ insignificant in all cases. For each model, we report two sets of coefficients. The first set is based on the whole sample (after taking lags, this is 1997(2)-2006(6)), and the second is based on the years of particularly high violence, 2001(1)-2004(12). The shorter sample is chosen for two reasons. First of all, we would like to check whether any of our results are sensitive to the structural break in late 2000. Secondly, as shown in Table 2 above, the correlations among the explanatory variables are generally very much lower over the shorter sample period than they are over the whole sample: there is a large rise in all of the series at the end of 2000, but after that the monthly correlation coefficients are not very large. Fitting a model to the shorter sample is a way of investigating whether the insignificance of a variable in the full sample regression is a consequence of multicollinearity.

Before discussing the results of individual models, it is important to note that the application of standard model selection criteria, such as the Schwartz-Bayesian Criterion or the Akaike Criterion (reported at the bottom of the table), does not reveal any one particular model as obviously preferable to the others. This is not surprising, given the high correlations among the alternative regressors. Nevertheless, the results of all the models are broadly consistent with each other. 
Fitting Model 1 to the full sample, we obtain significant negative coefficients on $\ln \left(1+P L K^{W N T}\right), \ln \left(1+I F K^{W N T}\right)$ and $\ln \left(1+I F K^{N R P}\right)$. The coefficient on reported Palestinian fatalities is -0.26 , a figure that remains more or less constant across all the model specifications. This implies that a rise in average monthly reported deaths from zero to the post-Intifada geometric mean (2.5) will eventually reduce tourist numbers to around $72 \%$ of their initial value. The corresponding sample means for reported and unreported Israeli deaths are 2.0 and 6.8 respectively; the estimated coefficients $(-0.13$ and -0.17$)$ imply that a simultaneous rise in both variables from zero to their respective sample means would eventually reduce tourist numbers to $24 \%$ of their initial value. However, the coefficients on reported and unreported Israeli fatalities are not significantly different from each other, which suggests that Israeli fatalities impact on tourist numbers regardless of whether they are reported or not. By contrast, the $\ln \left(1+P L K^{N R P}\right)$ coefficient is very close to and insignificantly different from zero, suggesting that Palestinian fatalities impact on tourist numbers only when they are reported. The results for the 2001-2004 sample are broadly similar: none of the individual regression coefficients is significantly different from the corresponding full sample coefficient; this is a feature common to all of the models. In general, our results are robust to restricting the sample to the shorter period. However, the short sample $\ln \left(1+I F K^{N R P}\right)$ coefficient is insignificantly different from zero, although it is still insignificantly different from the $\ln \left(1+I F K^{W N T}\right)$ coefficient.

The results of Model 2 are consistent with those of Model 1, in that the two significant variables are $\ln \left(1+P L K^{W N T}\right)$ and $\ln (1+I F K)$ : the figures that matter are reported Palestinian fatalities and total Israeli fatalities, regardless of whether these are reported or not. Although the information criteria for Model 2 are very marginally better, there is no strong evidence about which functional form is to be preferred.

In Model 3, which disaggregates IFK by location, there are significant negative coefficients on both fatalities in the West Bank and Gaza and fatalities west of the Green Line. They are significantly different from neither each other nor the coefficient on total fatalities in Model 2. This suggests that the location of deaths does not play an important role in conditioning tourist perceptions.

In Model 4, which disaggregates IFK by the manner of attack, there are significant negative coefficients on both deaths in suicide bomb attacks and deaths in other attacks. The difference between the two coefficients is marginally significant in the full sample version of the model, and in fact the coefficient on $\ln \left(1+I F K^{O T H}\right)$ is the larger of the two. This seems to contradict the assumption that suicide attack casualties have at least as much impact on tourist numbers as other types of casualty. However, one explanation for the relatively small 
coefficient on $\ln \left(1+I F K^{S U I}\right)$ is that it is an imperfect proxy for the number of suicide bomb attacks. In the full sample version of Model 5, which replaces $\ln \left(1+I F K^{S U I}\right)$ with the number of attacks, NSU, the information criteria are very slightly better than in Model 4, although no statistical significance can be attached to this difference. The NSU coefficient (-0.13) implies that a single suicide bomb attack every month reduces tourist numbers to around $88 \%$ of the level they would otherwise reach.

The dummy variables are statistically significant in all forms of the model. The dummy for March 2002 is positive, indicating that the atypically high level of violence in that month had a less than proportional effect on tourist numbers. The dummy for OctoberNovember 2000 is negative, indicating that the onset of the Intifada period had a temporary negative impact on tourist numbers in addition to the actual and reported casualties at this time. The dummy for February-March 2003 is also negative, reflecting the impact of the Gulf War on tourist numbers in Israel. In fact, this is the largest single effect of all. ${ }^{7}$

Given the absence of a significant media effect in the impact of Israeli casualties, there does not seem to be a strong case for arguing that cultivation theory is relevant to television reporting of the Israeli-Palestinian conflict. Still, reports of Palestinian casualties do have a large and significant impact; altogether, this suggests that viewers are generally rational and well informed, but rely on journalists' judgement to indicate which events involving Palestinian casualties are politically significant.

\subsection{Dynamics and model simulation}

Rather than discussing the individual regression coefficients in Appendix 2 in detail, we illustrate the dynamic properties of our regressions in Figure 3. This figure depicts results implicit in the full sample version of Model 5, but not results from other model. However, the stylized facts discussed here also apply to the other models. The three charts in Figure 3 plot the hypothetical response of the dependent variable to a temporary (one-month) increase in each of the three statistically significant variables, $\ln \left(1+P L K^{W N T}\right), \ln \left(1+I F K^{O T H}\right)$ and NSU, by one unit. In all three cases, the effect of a temporary increase in actual or reported violence is dissipated very quickly. Within four or five months, tourist numbers have recovered to a level very close to their starting point (zero in the charts). This means that variations in the level of violence - both increases and decreases - are transmitted very quickly into changes in the number of tourists. Tourist number dropped very quickly at the start of the Intifada, but they have recovered equally quickly during the relative calm of 2005-6.

Another way of exploring the dynamics of the model is to simulate counterfactual time series for $\ln (T I S / T E U)$ under the assumption that (i) there was no reported violence over 
1997-2006 or (ii) there was no actual or reported violence over this period. Having done so, it is possible to calculate the ratio of the hypothetical level of TIS to its actual level in both cases. Figure 4 plots the two ratios, based on the full sample coefficients in Model 5. At the peak of the violence in 2002, tourist numbers would have been about twice as high if reports of Palestinian casualties had been censored. In the absence of any violence, actual or reported, tourist numbers would have been about five times as high during this period. More recently the intensity of the conflict has been relatively low, and the ratio for no actual or reported violence has fallen to around 1.4.

Figures 3-4 here

\subsection{Alternative model specifications ${ }^{8}$}

The interpretation of the results above depends on the assumption that the violence in Israel has no effect on American tourism in Europe. Europe has experienced some violence over the sample period, and this might be correlated with the intensity of the Arab-Israeli conflict, although the level of European violence is tiny in comparison. One way of testing the robustness of our conclusions is to replace European tourist data with data from another part of the world. For this reason, we compare the results of the Table 5 regressions with a corresponding set of results using US tourist departures for Oceania (TOC) in place of TEU. Figure 5 illustrates the alternative dependent variable, $\ln (T I S / T O C)$. It can be seen that there is a high degree of correlation between $\ln ($ TIS/TOC) and $\ln ($ TIS/TEU), although of course the seasonal components of the two series are rather different. Table 6 summarises the results from the $\ln ($ TIS/TOC) regressions. For each model, the table reports F-tests for the joint significance of the conflict variables (excluding the dummies) in the $\ln (T I S / T O C)$ regressions, and also their joint significance in corresponding regression equations for $\ln (T E U / T O C)$. This second set of F statistics tests whether changing the numerator in the Israeli tourist regressions makes a significant difference to the results. The conflict variables are always significant in the $\ln ($ TIS/TOC) models, and never significant in the $\ln ($ TEU/TOC) models; from this we conclude that our results are not being driven by the choice of a particular denominator.

\section{Figure 5 and Table 6 here}

We also test whether the addition of reported violence series from other news channels makes a significant difference to our results. There are some differences in the reporting of the violence across the three major channels. In particular, World News Tonight mentions Palestinian casualties more frequently than the other two. Over the period 1997(1)-2006(6), World News Tonight mentioned a specific number of Palestinian fatalities in $39.5 \%$ of the months; the corresponding figure for the CBS Evening News is only $30.7 \%$. Specific numbers 
of Palestinian deaths were hardly ever mentioned on the NBC Nightly News. When we add to Model 2 the number of fatalities reported on the CBS Evening News (that is, the variables $\ln \left(1+P L K^{C B S}\right)$ and $\left.\ln \left(1+I F K^{C B S}\right)\right)$, these additional variables are jointly and individually insignificant, while $\ln \left(1+P L K^{W N T}\right)$ remains significant. The same is true of Models 3-5. This may reflect the viewing habits of potential tourists: perhaps they take a particular interest in the channel that provides the most detailed information about the conflict (the $A B C$ ), or in local channels taking news feed from the ABC. The theoretical model of Gentzkow and Shapiro (2006) shows that a rational Bayesian consumer will give more credibility to a media source when it confirms her prior expectations. If potential visitors to Israel have a prior belief that it is a dangerous place, then they may well pay particular attention to media outlets that give the highest profile to the violence there.

Finally, we test whether retrospective reports of the violence have an impact on tourist figures. Sometimes, the same fatalities are reported on more than one occasion, or a report will mention the total number of fatalities over the last few months or years. Such reports are relatively infrequent: in the case of World News Tonight, retrospective Palestinian deaths are reported in only $11.4 \%$ of the months, and retrospective Israeli and foreign deaths in only $8.8 \%$. Adding these retrospective fatality series to Models 1-5 does not produce significant coefficients on the extra variables, and the size and significance of the other variables is largely unaffected. Retrospectively reported fatalities constitute a broad, somewhat heterogeneous category, and it is possible that greater disaggregation would produce some significant coefficients. However, with so few non-zero observations in our sample, it would be difficult to disaggregate further without a serious risk of spurious results from data-mining.

\section{Conclusion}

Analysis of time-series and cross-sectional Israeli tourist data reveals some of the factors driving people's attitudes towards the risk associated with travel to a conflict region. Timeseries analysis of tourist flows from the United States shows that since the onset of the Intifada variations in conflict intensity have affected tourist volumes. These results reinforce previous studies of the wider macroeconomic impact of the Intifada, for example Fielding (2003) and Eckstein and Tsiddon (2004). As a consequence, we can expect even a partial reduction in violent conflict in the region increase tourism revenue. As returning tourists boost local incomes they may create stakeholders in the continuation of the peace process. This could be grounds for optimism regarding a gradual resolution of the conflict.

We find that different dimensions of the conflict have heterogeneous effects on tourist flows. There is also heterogeneity with regard to whether it is the actual or reported intensity 
of a certain dimension of the conflict that matters. An increase in the frequency of actual Israeli casualties reduces tourist numbers substantially; conditional on these figures, attacks reported on network television channels make no significant difference. By contrast, it is the reported number of Palestinian deaths - not the actual number - that causes a decline in tourism. Further disaggregation of casualty figures (for example, by location or by the type of attack) indicates that attacks of all kinds have a substantial impact on tourist numbers. It is possible to square this result with a model of economically rational tourists: for example, tourists could rely on the qualitative judgement of journalists to inform them which conflict events are the most politically significant. Nevertheless, it does demonstrate that television has a substantial impact on economic behaviour.

\section{Notes}

${ }^{1}$ As acknowledged in Brück and Wickström (2004), such psychological effects are likely to be particularly important when we are modelling people's responses to risks to life and limb.

${ }^{2}$ By contrast, Burger and Sturm (2005) construct a model of the German macro-economy conditional on the number of German television media reports of conflicts around the world. However, they do not compare this with a model using actual data from the conflicts that are partially reported.

${ }^{3}$ The regression specification here with is similar in spirit to that of Fleischer and Buccola (2002), who analyze total foreign demand for Israeli hotel accommodation up to 1999 as a function of a single "terror index", but differs from their model in points of detail. We do not find any significant coefficient on economic variables in our regression equation.

${ }^{4} N Y=1$ if either Rosh Hashanah or Yom Kippur occur in the month; otherwise $N Y=0$.

${ }^{5}$ One disadvantage of the data that we use is that they include business visitors in the total, and this should be noted as a caveat. There are no appropriately disaggregated data available at a frequency higher than once every two months.

${ }^{6}$ The B'Tselem data do not cover violence along the Lebanese border, but this area does not attract such a large proportion of the foreign tourist market as it does of the domestic one.

${ }^{7}$ The dummy variable for March 2002 is omitted from the model when the 2001-2004 sample is used, because it is collinear with the seasonal effects.

${ }^{8} \mathrm{We}$ also explored the effect of replacing our measure of the number of American tourists visiting Israel with the number of American tourist person nights (indicating the number of tourists in Israel times the number of nights they stayed); this time series is also available on the CBS website. The correlation between the two alternative dependent variables is 0.98 . The results using the alternative dependent variable are very similar to the ones reported here; the 
main difference is in the $\ln \left(1+P L K^{W N T}\right)$ coefficients, which are about 3-4 percentage points smaller, but still significant at the 5\% level. 


\section{References}

Brück, T. and B-A. Wickström, 2004. The Economic Consequences of Terror. European Journal of Political Economy 20, 293-300.

Burger, H. and J-E. Sturm, 2005. Assessing the Cost of Terrorism. Media Tenor Quarterly 1.

Chiricos, T., S. Eschholz and M. Gertz, 1997. Crime, News and Fear of Crime. Social Problems 44, 342-357.

De Jong, P., 1997. The Scan Sampler for Time Series Models. Biometrika 84,929-937.

Drakos, K. and A. Kutan, 2003. Regional Effects of Terrorism on Tourism in Three Mediterranean Countries. Journal of Conflict Resolution 47, 621-641.

Drakos, K., 2004. Terrorism-induced Structural Shifts in Financial Risk. European Journal of Political Economy 20, 435-446.

Eckstein, Z. and D. Tsiddon, 2004. Macroeconomic Consequences of Terror: Theory and the Case of Israel. Journal of Monetary Economics 51, 971-1002.

Eldor, R. and R. Melnick, 2004. Financial Markets and Terrorism. European Journal of Political Economy 20, 367-386.

Enders, W. and T. Sandler, 1991. Causality between Trans-national Terrorism and Tourism: The Case of Spain. Terrorism 14, 49-58.

Enders, W., T. Sandler and G. Parise, 1992. An Econometric Analysis of the Impact of Terrorism on Tourism. Kyklos 45, 531-554.

Fielding, D., 2003. Modelling Political Instability and Economic Performance: Israeli Investment during the Intifada. Economica 70, 159-186.

Fleischer, A. and S. Buccola, 2002. War, Terror, and the Tourism Market in Israel. Applied Economics 34, 1335-1343.

Frey, B., S. Luechinger and A. Stutzler, 2004. Calculating Tragedy: Assessing the Costs of Terrorism. Working Paper 205, Institute for Empirical Research in Economics, University of Zurich.

Gentzkow, M. and J. Shapiro, 2006. Media Bias and Reputation. Journal of Political Economy 114, 280-316.

Gerbner, G. and L. Gross, 1976. Living with Television: the Violence Profile. Journal of Communication 26, 173-199.

Gross, K. and S. Aday, 2003. The Scary World in Your Living Room and Neighborhood: Using Local Broadcast News, Neighborhood Crime Rates, and Personal Experience to Test Agenda Setting and Cultivation. Journal of Communication 53, 411-426.

Harvey, D. and Mills, T. 2002. Unit Roots and Double Smooth Transitions. Journal of Applied Statistics 29, 675-683. 
Jaeger, D.A. and M.D. Paserman, 2005. Israel, the Palestinian Factions, and the Cycle of Violence. Working Paper 23, Department of Economics, College of William and Mary.

Kalaitzandonakes, N., L. Marks and S. Vickner, 2004. Media Coverage of Biotech Foods and Influence on Consumer Choice. American Journal of Agricultural Economics 86, 1238-1246.

Leybourne, S., Newbold, P. and Vougas, D., 1998. Unit Roots and Smooth Transitions. Journal of Time Series Analysis 19, 83-97.

Mazzocchi, M., 2004. Modelling Consumer Reaction to Multiple Food Scares. Paper presented to the $78^{\text {th }}$ annual meeting of the Agricultural Economics Society, Imperial College, London, England.

Piggott, N. and T. Marsh, 2004. Does Food Safety Information Impact U.S. Meat Demand? American Journal of Agricultural Economics 86, 154-174.

Romer, D., K. Jamieson and S. Aday, 2003. Television News and the Cultivation of Fear of Crime. Journal of Communication 53, 88-104.

Sloboda, B., 2003. Assessing the Effects of Terrorism on Tourism by Use of Time Series Methods. Tourism Economics 9, 179-190.

Tversky, A. and D. Kahneman, 1973. Availability: a Heuristic for Judging Frequency and Probability. Cognitive Psychology 5, 207-232.

Verbeke, W. and R. Ward, 2001. A Fresh Meat Almost Ideal Demand System Incorporating Negative TV Press and Advertising Impact. Agricultural Economics 25, 359-374. 
Table 1: Alternative Model Specifications

Reported Palestinian deaths $\left(P L K^{W N T}\right)$

Non-reported Palestinian deaths $\left(P L K^{N R P}\right)$

Total Palestinian deaths $(P L K)$

Reported Israeli deaths (IFK ${ }^{W N T}$ )

Non-reported Israeli deaths $\left(I F K^{N R P}\right)$

Total Israeli deaths (IFK)

Israeli deaths west of the Green Line $\left(I F K^{I S R}\right)$

Israeli deaths in the West Bank (IFK $\left.{ }^{W B G}\right)$

Israeli deaths: not suicide bombs (IFK ${ }^{\mathrm{OTH}}$ )

Israeli deaths: suicide bombs $\left(I F K^{S U I}\right)$

Number of suicide bomb attacks (NSU)

$\begin{array}{ccccc}\text { Model } & \text { Model } & \text { Model } & \text { Model } & \text { Model } \\ 1 & 2 & 3 & 4 & 5 \\ \times & \times & \times & \times & \times \\ \times & & & & \\ & \times & \times & \times & \times \\ \times & \times & \times & \times & \times \\ \times & & & & \\ & \times & & & \\ & & \times & & \\ & & \times & & \times \\ & & & \times & \times\end{array}$

\section{Table 2: Selected Correlations across the Explanatory Variables}

The sample is 1997(1)-2006(6). Standard deviations are reported on the main diagonal.

The figures in parentheses are conditional on an intercept shift in October 2000.

$\begin{array}{lcccc}\ln \left(1+P L K^{W N T}\right) & 1.25(1.12) & & & \\ \ln \left(1+I F K^{W N T}\right) & 0.70(0.62) & 1.15(1.01) & & \\ \ln \left(1+P L K^{N R P}\right) & 0.42(0.07) & 0.46(0.12) & 1.60(0.77) & \\ \ln \left(1+I F K^{N R P}\right) & 0.46(0.24) & 0.40(0.13) & 0.75(0.42) & 1.10(0.80) \\ & & & & \\ \ln \left(1+I F K^{I S R}\right) & \ln \left(1+I F K^{W B G}\right) & \ln \left(1+I F K^{\text {OTH }}\right) & \ln \left(1+I F K^{S U I}\right) \\ \ln \left(1+I F K^{I S R}\right) & 1.19(0.98) & & & \\ \ln \left(1+I F K^{W B G}\right) & 0.59(0.33) & 1.06(0.76) & & \\ \ln \left(1+I F K^{\text {OTH }}\right) & 0.62(0.39) & 0.94(0.88) & 1.09(0.80) & \\ \ln \left(1+I F K^{\text {SUI }}\right) & 0.91(0.88) & 0.56(0.33) & 0.47(0.19) & 1.19(1.02)\end{array}$

Table 3: Stationarity Test Statistics for $\ln (T I S / T E U)$

The sample is 1996(4)-2006(6).

deterministic components

intercept

LNV smooth transition

Harvey \& Mills smooth transition
ADF $t$

$-2.55 *$

$-7.27 * * *$

$-7.54 * * *$ lags

2

1

1

*** significant at $1 \% ; *$ significant at $10 \%$. 
Table 4: Augmented Dickey-Fuller Test Statistics for the Explanatory Variables

All ADF regressions include an intercept and trend. The sample is 2001(1)-2006(6).

$$
\begin{aligned}
& \text { variable } \\
& \ln \left(1+P L K^{N R P}\right) \\
& \ln \left(1+I F K^{N R P}\right) \\
& \ln (1+P L K) \\
& \ln (1+I F K) \\
& \ln \left(1+I F K^{I S R}\right) \\
& \ln \left(1+I F K^{W B G}\right) \\
& \ln \left(1+I F K^{\text {OTH }}\right) \\
& \ln \left(1+I F K^{S U I}\right)
\end{aligned}
$$$$
\text { ADF } t
$$

*** significant at $1 \% ; *$ significant at 5\%; * significant at $10 \%$. 
Table 5: Steady-State Coefficients from the $\ln (T I S / T E U)$ Regression Equations

Each regression also includes month, Passover and New Year effects. The full sample is 1997(2)-2006(6).

Model 1

full sample 2001-2004 full sample 2001-2004 full sample

$\ln \left(1+P L K^{W N T}\right)$

$\ln \left(1+I F K^{W N T}\right)$

$\ln \left(1+P L K^{N R P}\right)$

$\ln \left(1+I F K^{N R P}\right)$

$\ln (1+P L K)$

$\ln (1+I F K)$

$\ln \left(1+I F K^{I S R}\right)$

$\ln \left(1+I F K^{W B G}\right)$

$\ln \left(1+I F K^{\text {OTH }}\right)$

$\ln \left(1+I F K^{S U I}\right)$

NSU

O/N 2000

Mar 2002

-3.02 -3.56

$1.41 \quad 2.67$

coeff.

$\begin{array}{llll}-0.26 & -3.44 & -0.20 & -2.77\end{array}$

$\begin{array}{lllll}-0.13 & -2.05 & -0.17 & -2.88\end{array}$

$\begin{array}{llll}0.03 & 0.60 & 0.09 & 0.90\end{array}$

$\begin{array}{llll}\mathbf{- 0 . 1 7} & \mathbf{- 2 . 4 2} & -0.10 & -1.02\end{array}$

F/M 2003

$-2.48-3.64$

$\mathrm{R}^{2}$

$\sigma$

$\mathrm{SBC}$

$\begin{array}{rr}0.93 & 0.95 \\ 0.16 & 0.15 \\ -2.69 & -2.46 \\ -3.39 & -3.51\end{array}$

$-3.39$

Test statistic $p$ values

Autocorr.

$\mathrm{ARCH}$

Jarque-Bera

0.44

0.15

0.76

0.89

Heterosked.

0.83
0.47
0.76

$\begin{array}{llllllll}-0.27 & -3.90 & -0.16 & -2.52 & -0.23 & -3.74 & -0.17 & -2.56\end{array}$

coeff.

$\begin{array}{llll}-0.02 & -0.23 & -0.03 & -0.36\end{array}$

$\begin{array}{lllll}0.04 & 0.64 & -0.04 & -0.53\end{array}$

0.04

$\begin{array}{lllll}-0.22 & -2.86 & -0.33 & -2.14\end{array}$

$$
\begin{array}{llll}
\mathbf{- 0 . 1 5} & \mathbf{- 2 . 4 5} & -0.14 & -1.45 \\
\mathbf{- 0 . 2 3} & \mathbf{- 3 . 0 6} & -0.16 & -1.58
\end{array}
$$

Model 4

\section{full sample 2001-2004}

coeff.

$-0.22-3.53$

$\begin{array}{ll}0.03 & 0.42\end{array}$

coeff

$\begin{array}{ll}-0.14 & -2.43\end{array}$

$\begin{array}{ll}-0.03 & -0.41\end{array}$

0.05

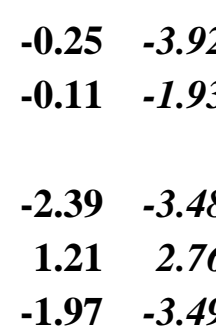

$\begin{array}{rr}-2.95 & -3.71 \\ 1.32 & 2.67 \\ -2.22 & -3.50\end{array}$

$\begin{array}{ll}-2.51 & -3.43\end{array}$

$\begin{array}{ll}1.26 & 2.73\end{array}$

$\begin{array}{ll}-1.68 & -3.54\end{array}$

$-2.02-3.56$

$\begin{array}{rr}0.93 & 0.96 \\ 0.16 & 0.14 \\ -2.73 & -2.55 \\ -3.43 & -3.60\end{array}$

0.94

0.16

$-2.70$

$-3.45$

0.21

0.56

0.12

0.94

0.96

0.35

0.30

0.41

0.03

0.78

0.96

$\begin{array}{rr}0.94 & 0.96 \\ 0.16 & 0.14 \\ -2.70 & -2.54 \\ -3.45 & -3.67 \\ & \\ 0.45 & 0.21 \\ 0.03 & 0.22 \\ 0.62 & 0.15 \\ 0.92 & \end{array}$

Model 5

full sample 2001-2004

coeff. $t$ coeff. $t$

$\begin{array}{llll}-0.22 & -3.65 & -0.18 & -2.90\end{array}$

$\begin{array}{lllll}0.07 & 0.94 & -0.01 & -0.08\end{array}$

$\begin{array}{llll}0.02 & 0.62 & 0.08 & 0.80\end{array}$

$\mathbf{0 . 2 2} \quad \mathbf{- 3 . 6 2} \quad-0.12 \quad-1.45$

$\begin{array}{llll}-0.13 & -2.21 & -0.12 & -1.77\end{array}$

$-2.15 \quad-3.33$

$2.04 \quad 3.68$

$\begin{array}{llll}-2.19 & -4.07 & -1.86 & -3.95\end{array}$ 
Table 6: Joint Significance of the Conflict Variables in the $\ln (T I S / T O C)$ and $\ln (T E U / T O C)$ Regressions

These figures are the p-values of F-tests for the joint significance of lags of the conflict variables.

\begin{tabular}{lcccc} 
& \multicolumn{2}{c}{$\ln ($ TIS/TOC $)$} & \multicolumn{2}{c}{$\ln ($ TEU/TOC) } \\
full sample & $\mathbf{2 0 0 1 - 2 0 0 4}$ & full sample & $\mathbf{2 0 0 1 - 2 0 0 4}$ \\
Model 1 & 0.000 & 0.001 & 0.610 & 0.996 \\
Model 2 & 0.000 & 0.001 & 0.433 & 0.983 \\
Model 3 & 0.000 & 0.003 & 0.591 & 0.642 \\
Model 4 & 0.000 & 0.002 & 0.787 & 0.947 \\
Model 5 & 0.000 & 0.001 & 0.418 & 0.470
\end{tabular}




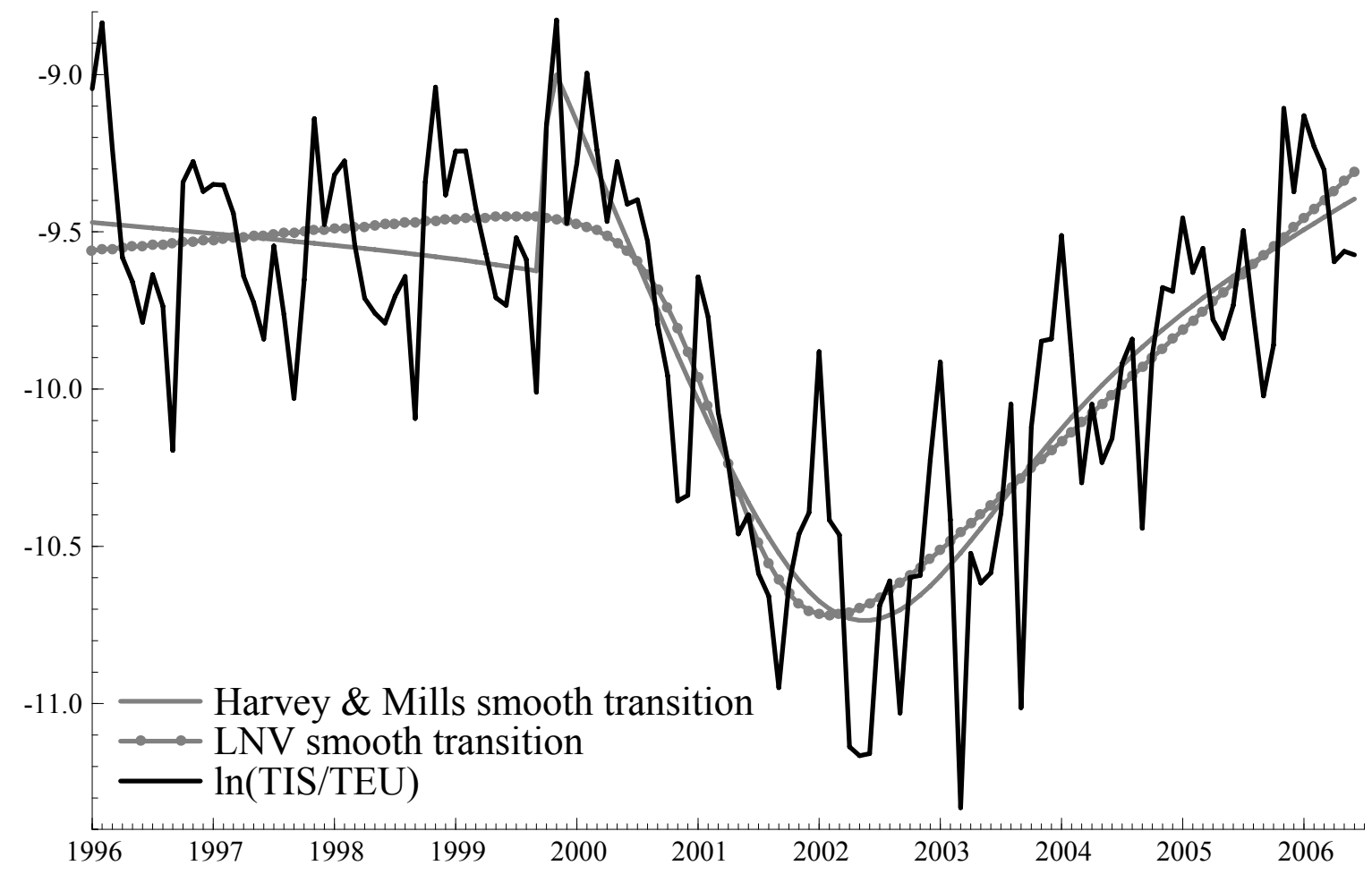

Figure 1: $\ln (T I S / T E U)$ with fitted smooth transitions
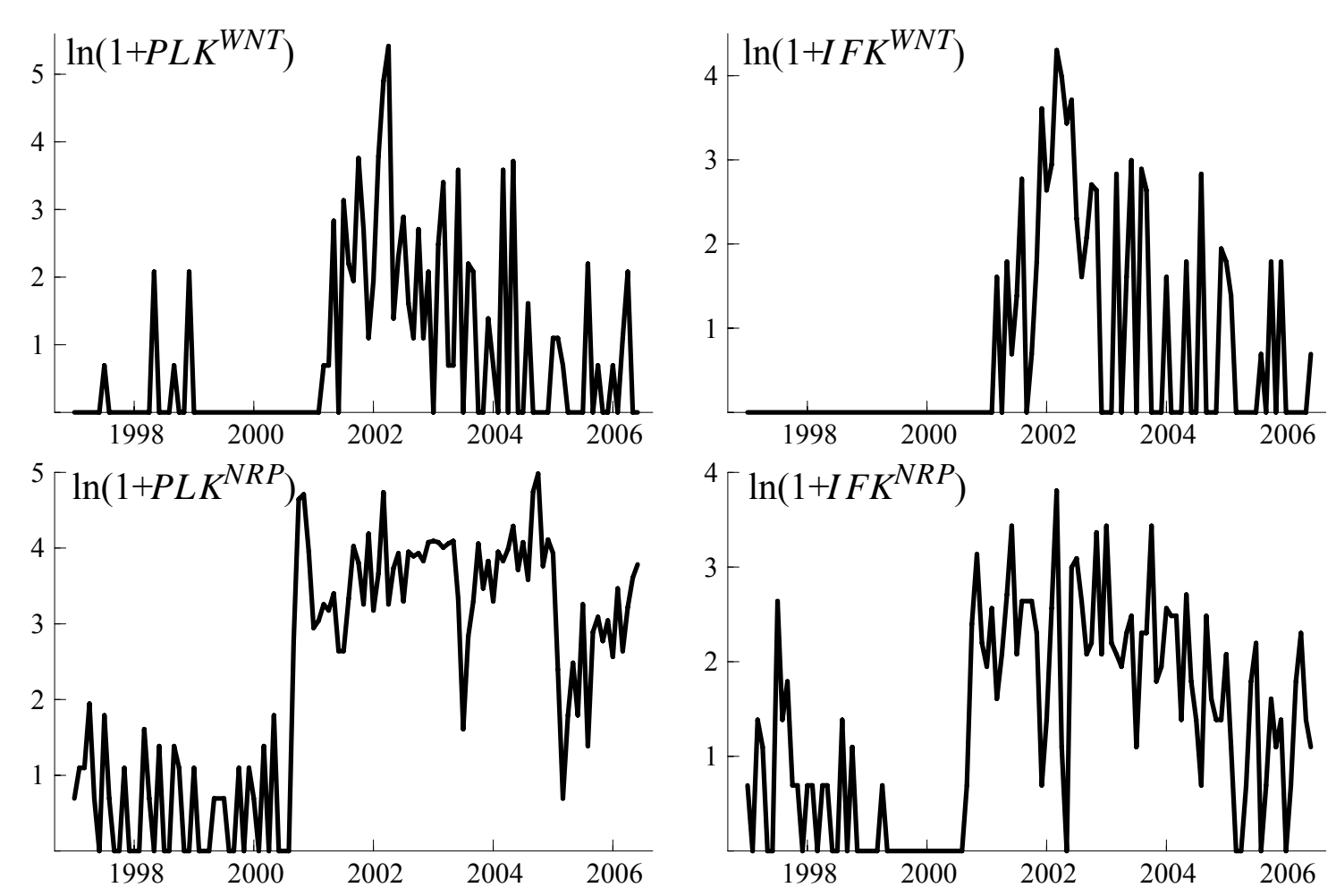

Figure 2: Selected conflict variables 

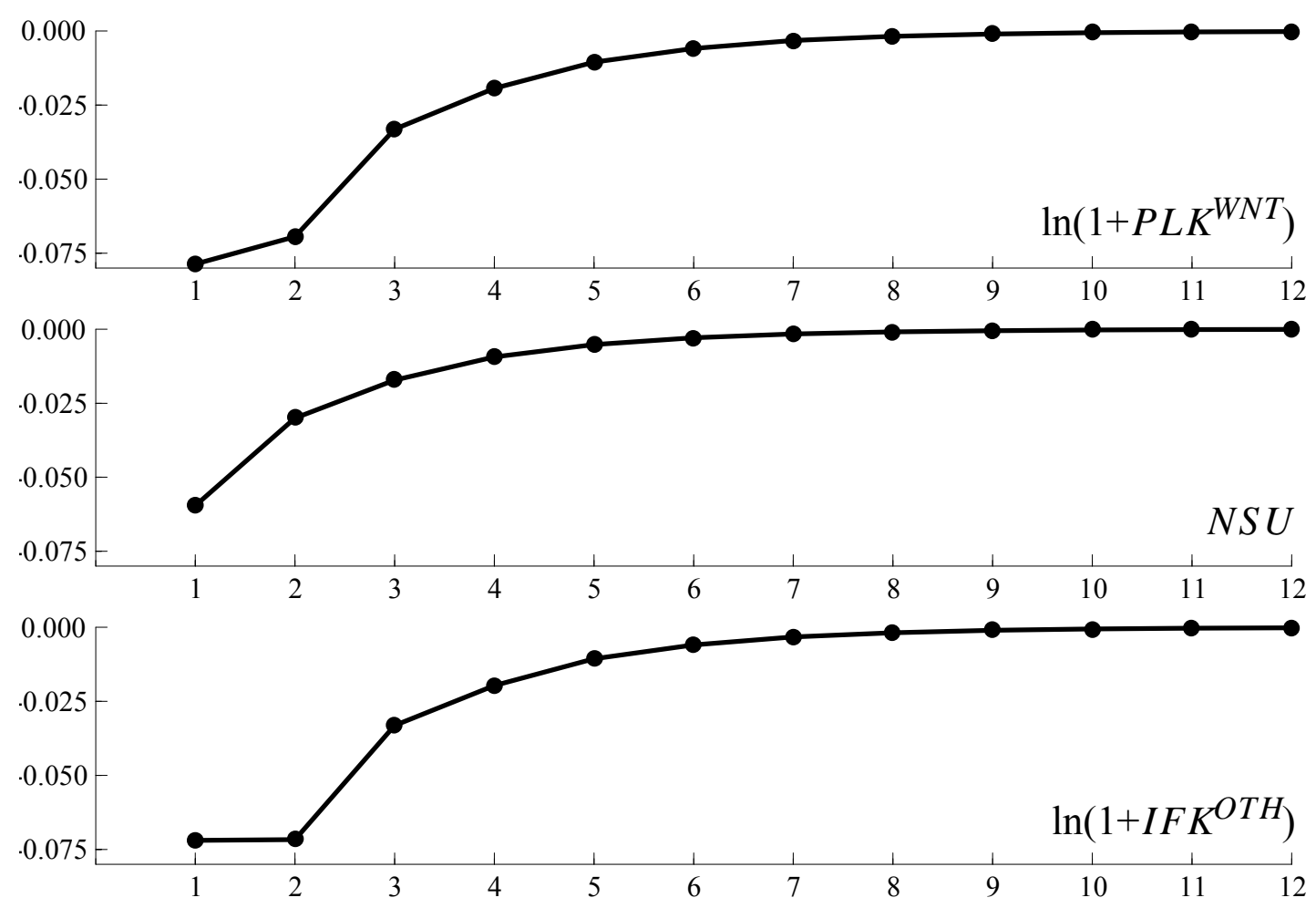

Figure 3: Impulse responses for temporary unit deviations, Model 5

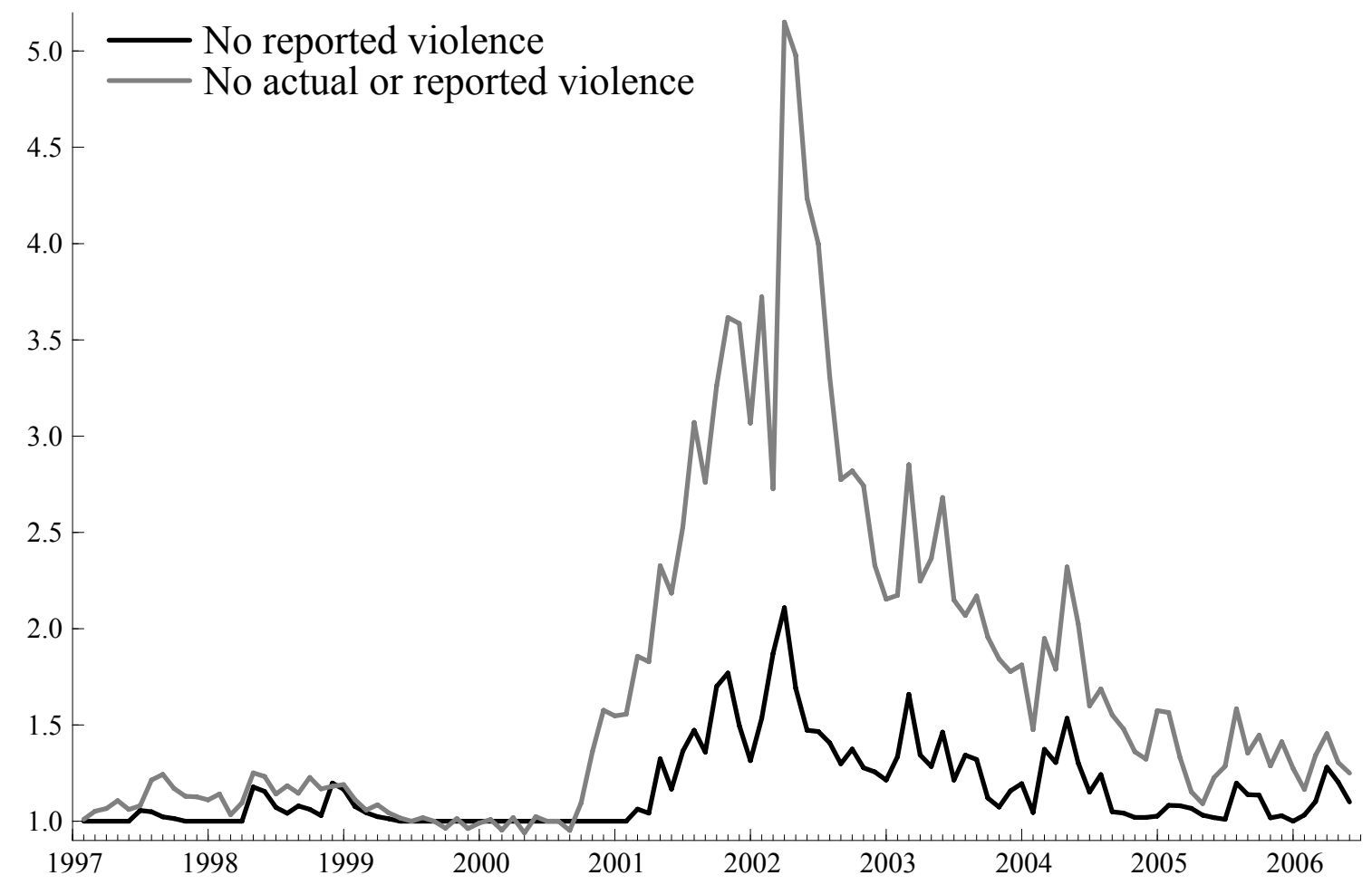

Figure 4: Ratios of hypothetical tourist numbers to actual tourist numbers, Model 5 


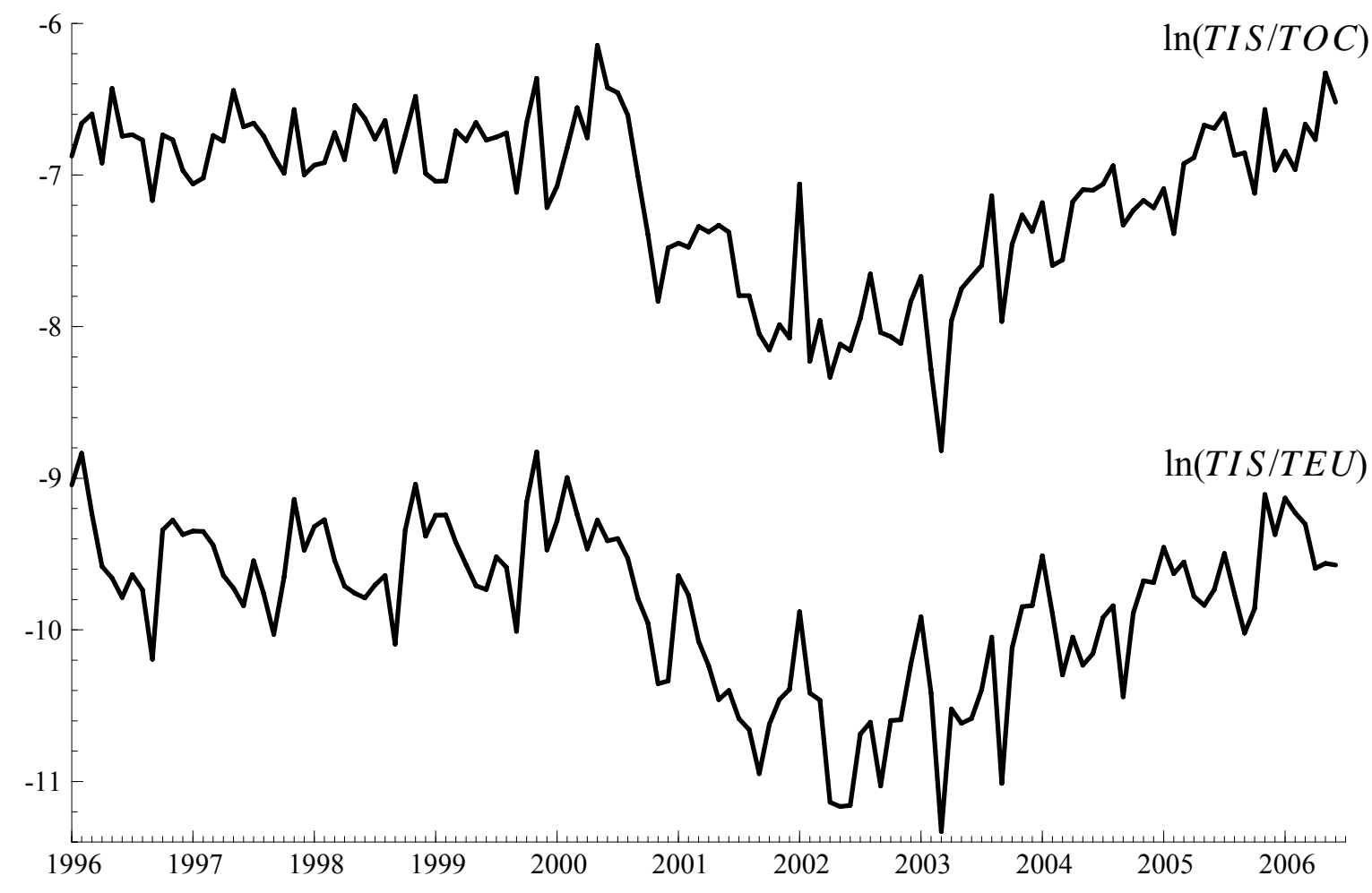

Figure 5: $\ln (T I S / T E U)$ and $\ln (T I S / T O C)$ compared 


\section{Appendices to Be Made Available on Request}

\section{Appendix 1}

Here we discuss the conceptual framework from which equation (1) in the main text is derived. This follows a standard discrete choice framework, as can be found in, for example, Maddala (1983). Our model concerns a population of American tourists who have already decided to take a vacation; now they are deciding where to go. Let the net utility an individual $i$ derives from taking a vacation in location $m \in\{1, \ldots, M\}$ in month $t$ be designated $v_{\text {imt }}$. We will assume that each person's utility is of the form:

$v_{i m t}=\mu_{m t}\left(\mathbf{Z}_{m t}, \varepsilon_{m t}\right)+u_{i m t}$

where $\mu_{m t}$ is the average level of utility from visiting location $m$ in month $t$ for the vacationing population and $u_{i m t}$ is an individual's idiosyncratic deviation from this average. $\boldsymbol{Z}_{m t}$ is a vector of identifiable time-varying factors that impact on one's net utility from a vacation in a particular location, and $\varepsilon_{m t}$ is a stochastic term reflecting the unpredictable component of the average utility level. We further assume that individual $i$ chooses location $m$ in period $t$ just if:

$v_{i m t}=\max \left(v_{i 1 t}, \ldots, v_{i M t}\right)$

It can be shown (Maddala, 1983) that if for any two locations $(m, n)$ the distribution of $u_{\text {imt }}$ is independent of that of $u_{i n t}$, and if each has a Weibull distribution, then the probability of any one randomly selected individual choosing location $m$ in period $t$ is:

$$
p_{\text {imt }}=\exp \left(\mu_{m t}\right) / \sum_{j=1}^{j=M} \exp \left(\mu_{j t}\right)
$$

or, in logarithmic form:

$$
\ln \left(p_{i m t}\right)=\mu_{m t}-\ln \sum_{j=1}^{j=M} \exp \left(\mu_{j t}\right)
$$

For a large population, the log-ratio of the number of people in period $t$ visiting location $m$ $\left(p_{m t}\right)$ to the number visiting location $n\left(p_{n t}\right)$ can therefore be written as:

$\ln \left(p_{m t} / p_{n t}\right)=\mu_{m t}\left(Z_{m t}, \varepsilon_{m t}\right)-\mu_{n t}\left(Z_{n t}, \varepsilon_{n t}\right)$

Location $m$ here is to be interpreted as Israel; location $n$ is to be interpreted as Europe. If we know the functional forms of $\mu_{m t}($.$) and \mu_{n t}($.$) , then we can fit equation (A5) to time-series$ data. We assume that it is possible to find a linear specification such that:

$\ln \left(p_{m t} / p_{n t}\right)=\left[\boldsymbol{Z}_{\boldsymbol{m} t}-\boldsymbol{Z}_{\boldsymbol{n} t}\right]^{\prime} \boldsymbol{B}+\varepsilon_{t}$ 
where $\varepsilon_{t}$ is a linear function of $\varepsilon_{m t}$ and $\varepsilon_{n t}$. We further assume that $\left[\boldsymbol{Z}_{m t}-\boldsymbol{Z}_{n t}\right]$ has three major components, as follows.

(i) Seasonal factors, which we will capture by a seasonally varying intercept. The seasonality in tourism demand in Israel is likely to arise partly from the weather, and partly from its desirability a place to be during specific religious festivals.

(ii) Cyclical variation that results from imperfect information about the relative enjoyability of Israeli tourist resorts. If some people know more than others about the quality of these resorts (for example, because they have been there before), then there is an information externality in their decision to go again. Such externalities are likely to create cycles of the kind modelled theoretically by Çelen and Kariv (2004). We will capture this effect through the inclusion of a lagged dependent variable, which according to the theory ought to have a coefficient in the interval $[0,1]$, that is, the time series ought not to exhibit a unit root. Our simple linear model is an approximation to the theory. Nevertheless, the main point is that with imperfect information there are cycles resulting from herding behaviour, but the herding effect does not persist indefinitely.

(iii) The anticipated net disutility arising from violence in Israel. This net disutility is likely to be a function of the sense of personal threat facing tourists, but may also reflect political sympathy for one side or another in the conflict. Hence, those dimensions of conflict intensity related directly to the sense of threat may impact on tourist flows differently from those dimensions of conflict intensity that are related only to the sympathy effect. Further, we make no a priori assumption about whether tourists react to actual variations in conflict intensity or only to variations in the intensity of reporting by a particular television news show. Finally, we allow any cultivation effect from awareness of a particular dimension of the conflict (actual or reported) to impact on tourist flows with a lag. Hence, equation (A6) is interpreted as a dynamic equation of the following form, corresponding to equation (1) in the main text:

$\beta(\mathrm{L}) \ln \left(p_{m t} / p_{n t}\right)=\boldsymbol{A}(\mathrm{L}) \boldsymbol{X}_{t}+\Sigma_{s} \theta_{s} \cdot h_{s t}+\phi_{1} \cdot P S_{t}+\phi_{2} \cdot N Y_{t}+\varepsilon_{t}$

$h_{s t}$ is a dummy for month $s, P S_{t}$ and $N Y_{t}$ are Jewish holiday dummies and $\boldsymbol{X}_{t}$ is a vector of different measures of actual and reported conflict intensity during the Intifada.

Equation (A7) omits any measure of the relative cost of visiting of the two locations. Data on hotel and restaurant prices in Europe and Israel are available, facilitating the construction of hospitality price real exchange rate series. However, such series are unlikely to be exogenous to total tourist volumes, and in this context there is no obvious instrument for 
hotel and restaurant prices. For this reason we tested for a relative cost effect using an aggregate consumer price real exchange rate. Specifically, we used the log of the ratio of the Israeli consumer price index to the Euroland consumer price index, scaled by the Shekel-Euro nominal exchange rate. Nominal exchange rate and price indices are reported by the Israeli Central Bureau of Statistics (www.cbs.gov.il), the Federal Reserve Bank of St Louis (http://research.stlouisfed.org/fred2) and the European Central Bank (www.ecb.int). Adding a real exchange rate term based on these data to equation (A7) produced no statistically significant coefficient. Substitution of the (probably endogenous) hospitality price real exchange rate for the aggregate consumer price real exchange rate made no difference to the insignificance of the relative cost term in the regression equation.

\section{References}

Çelen, B. and Kari, S., 2004. Observational Learning under Imperfect Information. Games and Economic Behavior 47, 72-86.

Maddala, G., 1983. Limited Dependent and Qualitative Variables in Econometrics. Cambridge University Press. 


\section{Appendix 2: The Full Set of Coefficients from the $\ln (T I S / T E U)$ Regression Equations}

\begin{tabular}{|c|c|c|c|c|c|c|c|c|c|c|c|c|c|c|c|c|c|c|c|c|}
\hline & \multicolumn{2}{|c|}{ whole sample } & \multicolumn{2}{|c|}{ 2001-2004 } & \multicolumn{2}{|c|}{ whole sample } & \multicolumn{2}{|c|}{$2001-2004$} & \multicolumn{2}{|c|}{ whole sample } & \multicolumn{2}{|c|}{ 2001-2004 } & \multicolumn{2}{|c|}{ whole sample } & \multicolumn{2}{|c|}{$2001-2004$} & \multicolumn{2}{|c|}{ whole sample } & \multicolumn{2}{|c|}{ 2001-2004 } \\
\hline & coeff. & $t$ & coeff. & $t$ & coeff. & $t$ & coeff. & $t$ & coeff. & $t$ & coeff. & $t$ & coeff. & $t$ & coeff. & $t$ & coeff. & $t$ & coeff. & $t$ \\
\hline $\ln (T I S / T E U)_{-1}$ & 0.410 & 4.8 & 0.188 & 1.4 & 0.390 & 4.6 & 0.226 & 1.8 & 0.358 & 4.2 & 0.228 & 1.8 & 0.355 & 4.1 & 0.184 & 1.5 & 0.349 & 4.1 & 0.230 & 1.6 \\
\hline $\ln (T I S / T E U)_{-2}$ & 0.138 & 1.7 & 0.217 & 1.8 & 0.140 & 1.8 & 0.161 & 1.5 & 0.117 & 1.5 & 0.149 & 1.3 & 0.123 & 1.6 & 0.167 & 1.6 & 0.113 & 1.5 & 0.129 & 1.0 \\
\hline $\ln \left(1+P L K^{W N T}\right)$ & -0.067 & -3.2 & -0.055 & -2.2 & -0.079 & -3.9 & -0.047 & -2.0 & -0.074 & -3.6 & -0.053 & -2.2 & -0.071 & -3.5 & -0.049 & -2.1 & -0.079 & -3.7 & -0.056 & -2.0 \\
\hline $\ln \left(1+P L K^{W N T}\right)_{-1}$ & -0.049 & -2.3 & -0.061 & -2.4 & -0.048 & -2.3 & -0.053 & -1.9 & -0.047 & -2.3 & -0.050 & -1.7 & -0.044 & -2.1 & -0.044 & -1.6 & -0.042 & -2.1 & -0.060 & -2.0 \\
\hline $\ln \left(1+I F K^{W N T}\right)$ & -0.065 & -2.6 & -0.057 & -1.9 & -0.049 & -1.9 & -0.021 & -0.6 & -0.037 & -1.3 & -0.014 & -0.4 & -0.039 & -1.4 & -0.013 & -0.4 & -0.004 & -0.1 & -0.005 & -0.1 \\
\hline $\ln \left(1+I F K^{W N T}\right)_{-1}$ & 0.005 & 0.2 & -0.042 & -1.4 & 0.042 & 1.6 & 0.005 & 0.1 & 0.059 & 2.1 & -0.011 & -0.3 & 0.053 & 1.8 & -0.004 & -0.1 & 0.039 & 1.4 & 0.001 & 0.0 \\
\hline $\ln \left(1+P L K^{N R P}\right)$ & 0.019 & 0.8 & -0.022 & -0.3 & & & & & & & & & & & & & & & & \\
\hline $\ln \left(1+P L K^{N R P}\right)_{-1}$ & -0.007 & -0.3 & 0.075 & 1.1 & & & & & & & & & & & & & & & & \\
\hline $\ln \left(1+I F K^{N R P}\right)$ & -0.031 & -1.2 & -0.032 & -0.7 & & & & & & & & & & & & & & & & \\
\hline $\ln \left(1+I F K^{N R P}\right)_{-1}$ & -0.047 & -1.7 & -0.026 & -0.6 & & & & & & & & & & & & & & & & \\
\hline $\ln (1+P L K)$ & & & & & 0.029 & 1.2 & 0.021 & 0.4 & 0.034 & 1.4 & 0.002 & 0.0 & 0.037 & 1.6 & 0.022 & 0.4 & 0.036 & 1.6 & 0.018 & 0.3 \\
\hline $\ln (1+P L K)_{-1}$ & & & & & -0.010 & -0.4 & 0.013 & 0.2 & -0.009 & -0.4 & 0.023 & 0.3 & -0.016 & -0.7 & 0.006 & 0.1 & -0.024 & -1.1 & 0.030 & 0.4 \\
\hline $\ln (1+I F K)$ & & & & & -0.026 & -0.9 & -0.121 & -1.7 & & & & & & & & & & & & \\
\hline $\ln (1+I F K)_{-1}$ & & & & & -0.076 & -2.4 & -0.081 & -1.3 & & & & & & & & & & & & \\
\hline $\ln \left(1+I F K^{I S R}\right)$ & & & & & & & & & -0.029 & -1.2 & -0.069 & -1.8 & & & & & & & & \\
\hline $\ln \left(1+I F K^{I S R}\right)_{-1}$ & & & & & & & & & -0.051 & -2.0 & -0.017 & -0.4 & & & & & & & & \\
\hline $\ln \left(1+I F K^{W B G}\right)$ & & & & & & & & & -0.039 & -1.2 & -0.051 & -0.9 & & & & & & & & \\
\hline $\ln \left(1+I F K^{W B G}\right)_{-1}$ & & & & & & & & & -0.082 & -2.5 & -0.048 & -1.0 & & & & & & & & \\
\hline $\ln \left(1+I F K^{\text {ОТН }}\right)$ & & & & & & & & & & & & & -0.064 & -2.1 & -0.077 & -1.6 & -0.072 & -2.5 & -0.053 & -1.1 \\
\hline $\ln \left(1+I F K^{\text {OTH }}\right)_{-1}$ & & & & & & & & & & & & & -0.069 & -2.2 & -0.053 & -1.3 & -0.047 & -1.6 & -0.021 & -0.5 \\
\hline $\ln \left(1+I F K^{S U I}\right)$ & & & & & & & & & & & & & -0.022 & -1.0 & -0.074 & -2.3 & & & & \\
\hline $\ln \left(1+I F K^{S U I}\right)_{-1}$ & & & & & & & & & & & & & -0.038 & -1.5 & -0.021 & -0.7 & & & & \\
\hline$N S U$ & & & & & & & & & & & & & & & & & -0.060 & -2.3 & -0.056 & -1.5 \\
\hline$N S U_{-1}$ & & & & & & & & & & & & & & & & & -0.009 & -0.5 & -0.021 & -0.8 \\
\hline O 2000 & -0.473 & -2.5 & & & -0.500 & -2.6 & & & -0.480 & -2.5 & & & -0.432 & -2.3 & & & -0.375 & -2.0 & & \\
\hline N 2000 & -0.891 & -4.7 & & & -0.889 & -4.7 & & & -0.836 & -4.2 & & & -0.814 & -4.3 & & & -0.783 & -4.1 & & \\
\hline M 2002 & 0.637 & 2.6 & & & 0.620 & 2.6 & & & 0.660 & 2.6 & & & 0.634 & 2.7 & & & 1.097 & 3.4 & & \\
\hline F 2003 & -0.414 & -2.2 & -0.472 & -2.4 & -0.343 & -1.9 & -0.358 & -1.7 & -0.332 & -1.8 & -0.451 & -2.0 & -0.310 & -1.7 & -0.394 & -1.9 & -0.412 & -2.4 & -0.437 & -2.2 \\
\hline M 2003 & -0.707 & -3.7 & -0.667 & -3.2 & -0.703 & -3.7 & -0.673 & -3.4 & -0.726 & -3.7 & -0.646 & -2.9 & -0.719 & -3.8 & -0.683 & -3.5 & -0.766 & -4.0 & -0.757 & -3.5 \\
\hline
\end{tabular}

